\title{
Oil spill remote monitoring by using remotely piloted aircraft
}

\author{
Aleksandrs Urbahs and Vladislavs Zavtkevics \\ Institute of Aeronautics, Riga Technical University, Riga, Latvia
}

\begin{abstract}
Purpose - This paper aims to analyze the application of remotely piloted aircraft (RPA) for remote oil spill sensing.

Design/methodology/approach - This paper is an analysis of RPA strong points.

Findings - To increase the accuracy and eliminate potentially false contamination detection, which can be caused by external factors, an oil thickness measurement algorithm is used with the help of the multispectral imaging that provides high accuracy and is versatile for any areas of water and various meteorological and atmospheric conditions.

Research limitations/implications - SWOT analysis of implementation of RPA for remote sensing of oil spills.

Practical implications - The use of RPA will improve the remote sensing of oil spills.

Social implications - The concept of oil spills monitoring needs to be developed for quality data collection, oil pollution control and emergency response.

Originality/value - The research covers the development of a method and design of a device intended for taking samples and determining the presence of oil contamination in an aquatorium area; the procedure includes taking a sample from the water surface, preparing it for transportation and delivering the sample to a designated location by using the RPA. The objective is to carry out the analysis of remote oil spill sensing using RPA. The RPA provides a reliable sensing of oil pollution with significant advantages over other existing methods. The objective is to analyze the use of RPA employing all of their strong points. In this paper, technical aspects of sensors are analyzed, as well as their advantages and limitations.
\end{abstract}

Keywords Oil spill, Oil spill remote sensing, Remote piloted aircraft

Paper type Research paper

\section{Introduction}

A rapid response is extremely necessary for oil spill situations and unauthorized discharges from ships, the detection and identification of vessels creating pollution. Given the seriousness of the problem, the European Maritime Agency analyses information about satellite radar monitoring by using "Clean Sea Net" software and on its website online provides information service on marine pollution for the authorities of European countries. Responsible national authorities may then use airborne or maritime assets to approach an oil slick, verify it and provide feedback. The actual service may certainly be improved by integrating additional observations, as well as new sensors and platforms, for example, remotely piloted aircraft (RPA).

\section{Evaluation of the possibilities of using remotely piloted aircraft}

In the energy sector, oil transportation by sea requires monitoring for safety and prevention of illegal pollution from ships. The systematic pollution of marine environment by oil

The current issue and full text archive of this journal is available on Emerald Insight at: www.emeraldinsight.com/1748-8842.htm

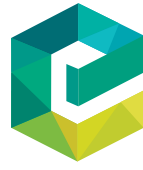

Aircraft Engineering and Aerospace Technology 91/4 (2019) 648-653

Emerald Publishing Limited [ISSN 1748-8842] [DOI 10.1108/AEAT-12-2017-0273] spilled from ships seriously damages the environment, disrupts the ocean-atmosphere exchange system, causes huge losses to tourism and leisure industry (Kostianoy et al., 2006). Taking into account the situation with various sources of water pollution, the main monitoring tasks are sea water management, data acquisition and processing. The monitoring of oil pollution requires the collection and accumulation of information on the actual parameters of the main environmental components and the preparation of forecasts for their qualitative changes in time.

The concept of monitoring needs to be developed for quality data collection, oil pollution control and emergency response. To carry out qualitative monitoring, it is necessary to establish a special system for monitoring, control, evaluation, short-term forecasting and predicting long-term trends in the state of an aquatorium in the context of determining the technological processes associated with shipping and oilfield development.
(C) Vladislavs Zavikevics and Aleksandrs Urbahs. Published by Emerald Publishing Limited. This article is published under the Creative Commons Attribution (CC BY 4.0) licence. Anyone may reproduce, distribute, translate and create derivative works of this article (for both commercial and non-commercial purposes), subject to full attribution to the original publication and authors. The full terms of this licence may be seen at http://creativecommons.org/licences/by/4.0/legalcode

Received 10 December 2017

Revised 13 November 2018

Accepted 13 November 2018 
Unfortunately, traditional monitoring of ships as sources of oil pollution in the Baltic Sea performed by satellite remote sensing, manned aircraft and coast guard ships is not effective for the oil transportation system (Figure 1). The main disadvantage of traditional remote sensing technologies is very late detection of oil pollution events (Figure 1).

Late detection means that oil pollution cleaning activities will not be effective. The application of RPA provides ecologically friendly oil transportation system in the energy sector and safe operation of ships. RPA can replace manned aircraft and coast guard ships that are engaged in oil pollution monitoring and provide high quality aerial information (Urbahs and Jonaite, 2013).

The mission of RPA can involve not only detection of oil contamination during surveillance but also other activities. The use of RPA will be expanded at the expense of payload which includes sensors required for participation in clean-up operations.

The tasks of oil pollution monitoring by using RPA can be divided into two groups: monitoring of sea aquatorium areas in emergency cases of oil pollution and daily monitoring of sea areas and objects to detect possible contamination by comparing videos, hyperspectral, multispectral images with normal pure water spectrum and the code range of possible oil product polluters. A strong role in remote sensing is also played by the detection of illegal discharges, especially from the point of view of large seabird mortality associated with such discharges (O'Hara et al., 2013). Using modern remote sensing payloads of the RPA, oil pollution can be monitored in the sea aquatorium on a $24-\mathrm{h}$ basis. It is important to divide the uses of remote sensing into the end use or objective, as the utility of the sensor is best defined that way (Fingas and Brown, 2011). A responsible organization needs the following information: location of the spill, implementation or support of the cleanup; the resolution or nature of the data needed may also be dictated. It specifies the information and receipt of pollution nature with the help of a multipurpose payload module, which is oriented towards a wider spectrum of pollution observation, oil slick distribution area assessment and sampling (Urbahs and Zavtkevics, 2017a, 2017b). The RPA can perform surveillance missions during weather-related flying limitations, because it flies below clouds. The application of the RPA depends on the type and size of airborne platform, type of sensor, and monitoring objectives. The innovative "swarm" of the RPA developed by the Massachusetts Institute of Technology monitors and even samples water quality (Telesetsky, 2016). The rapid development of microelectronics and microprocessors, battery

Figure 1 Position of the RPA in comparison with other remote sensing means

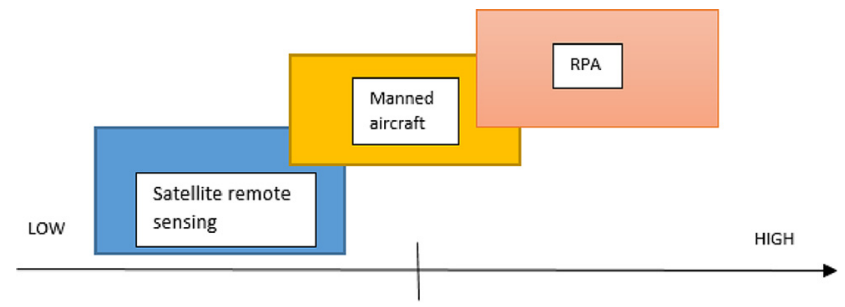

Actuality of received data and transmittion speed technology, global positioning system (GPS) and navigation systems together with reduced costs over the last five years have all helped in triggering an unprecedented demand for and growth in the use of the RPA platforms for many civilian applications (Colomina and Molina, 2014). During the execution of a flight on a particular route, the automatic system or operator shall use a video camera. There are serious problems of oil spill remote sensing, for instance, some sensors and sensor outputs require extensive processing to make the data useful for many purposes. Several general reviews of oil spill remote sensing have already been published (Fingas and Brown, 2014).

Remote sensing with the help of RPA has some advantages from the point of view of monitoring oil pollution in the sea; however, there are such problems as payload weight, narrow camera coverage for a single image, long image processing procedure. The objective of RPA use optimization is to utilize all the strengths and minimize the weaknesses.

The further increase of oil spot motion is determined by the wind and superficial turbulence diffusion of the stream. RPA perform the monitoring of oil slick distribution on the water surface and use the data obtained through the visual map of motion process, e.g. drift and oil slicks, which is determined by the wind, currents and surface condition. For oil slick motion correction, which is calculated by using an analytical calculation algorithm, the obtained monitoring data are converted into information on the map.

When detecting the site of oil distribution on the water surface, the automatic control system sends the RPA to the aquatorium monitoring area. Monitoring is carried out with the help of complex detection methods involving the use of video cameras, thermal cameras and a multispectral camera.

The approximate film thickness of possible pollution can be determined by using the expected oil spot color code table. The use of tables in the area of observation with a Visible and NearInfrared (VNIR) camera allows setting the initial stage of pollution detection and creating a model of oil slick distribution.

The reliable results of the remote sensing of oil pollution can be received by using the RPA payload with integrated multisystem sensors. The next stage includes initial clarification of information on pollution obtained by the RPA. The prognostic value of oil location and distribution on the water surface is computed analytically using the wind and current data, as these factors affect the spread of floating oil. The speed of oil slick movement depends on many factors (Urbahs and Zavtkevics, 2014).

\section{Remotely piloted aircraft observation results}

Because of errors inherent in the predictive petroleum movement, the automatic system plans a systematic search to set the presence or absence of oil on the water surface in the area. Regular slick video, spectral, thermal or photographic recording on the water surface may be valid for the transmission of information on the essential characteristics of the pollution to the emergency command center and supervisory service.

At this stage, there occurs the correction of analytically calculated distribution forecast, and it is defined as oil spot physicochemical characteristics based on parameters calculated from the data received by the RPA in real time (oil spot radius is received with the help of reliable time-cameras in real time). Floating oil slicks tend to extend and orientate parallel to the 
wind direction by taking on a shape of long and narrow strips, which are typically situated 30-50 meters from each other. To increase the probability of oil slick detection, it is recommended to organize a "parallel search" in the transverse direction with respect to the prevailing wind (Figure 2).

The results of RPA observation compared with the information obtained during a previous flight can also provide an overview of the situation at certain time. Appropriate methods for collecting information, its recording and submission will vary depending on the extent of environmental pollution and the level of detail needed for flying reconnaissance for a defined objective set by the algorithm with adjustable time intervals (Figure 3 ).

According to the data received from the RPA executing the flight plan, the correction algorithm implements the conversion of spilled oil volume. The RPA payloads include a GPS receiver with the help of which the border points of slick side coordinates are defined in certain time intervals. It automatically calculates radius changes $\Delta r$ at the time interval:

$$
\Delta t=t_{2}-t_{1}
$$

where:

$\Delta t$ represents the time interval;

$t_{1}$ time (seconds), when the first coordinates are defined; and $t_{2}$ time (seconds), when the second coordinates are defined.

$$
\Delta r=r\left(t_{2}\right)-r\left(t_{1}\right)
$$

where:

Figure 2 Parallel search

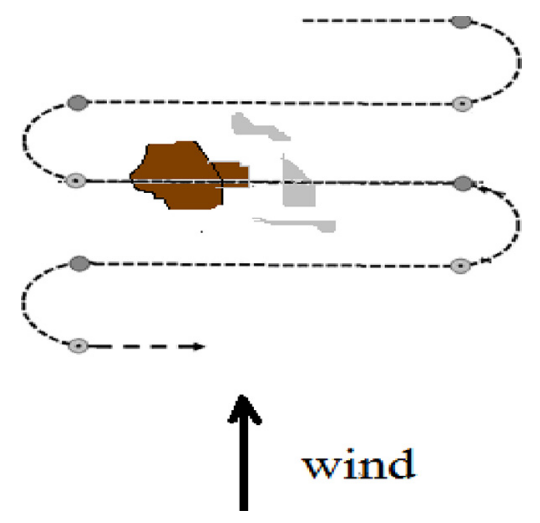

Figure 3 Algorithm for a forecast of oil slick distribution

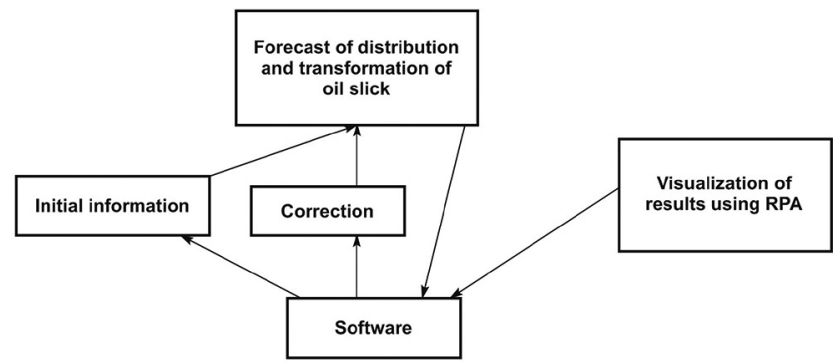

$\Delta r$ represents the radius changes at the time interval; $r\left(t_{1}\right)$ radius at the time $t_{1}$; and

$r\left(t_{1}\right)$ radius at the time $t_{2}$.

It also computes the difference between the analytical forecast of a slick and the actual radius for the calculation of forecast confidence degree, or performs a conversion to determine, if necessary, other parameters (viscosity, oil film thickness).

Performing the monitoring of sea aquatorium in case of technogenic emergency, the RPA transmits in real-time the changes in emergency object coordinates, discharge termination and oil flow on the water surface (for example, as a result of source elimination, changes in distribution speed, changes in the speed and course of a ship discharging oil products). It is also intended for the correction condition of an oil slick and the possibility that new spots may appear in the calculation process.

Oil location prediction comes together with the data of the wind and stream existence, as these factors affect the floating oil motion. A possible oil slick detection area is formed not only with account of the presence of the wind, but also with account of the history from the beginning of the accident and the moment for which the forecast is given. Oil slick movement is formed by the vector of oil pollution zone geometric center, which shows the sum value of current (tidal and drifting on the wind) velocity. Modeling of an oil spill is not a simple task, mainly because of the number of factors influencing the trajectories of pollutants: sea currents, winds, and even the gravitational force or surface tension of water (Aznar and Sempere, 2014). Having processed the data received after executing the RPA flight plan, the correction algorithm will be implemented for the slick center correction in real time. The RPA payloads and installed GPS device help to predict a very important parameter which represents a correction of distribution analytical calculations used for an oil spot - spot front edge. As the oil slick is spreading on the surface unevenly because of external influences (water flow, wind, waves), after the processed data have been received, the coordinates of oil slick vertices are determined and a center of gravity is calculated by using the gravitational method. Centers of gravity, which have been received after the results of monitoring in certain time intervals through the analytical calculation, allow calculating the direction and the actual speed of slick movement. Thus, on the basis of the information received through the RPA, which takes into account the prevailing winds and currents, it is possible to predict the speed and direction of floating oil motion from the location which is known for the next point of time and implement a predictable vector correction.

Using the results of the executed RPA flight plan, the criteria for determining the duration of different oil distribution phases can be defined (Urbahs and Zavtkevics, 2017a, 2017b). The VNIR digital camera and IR images, multispectral and hyperspectral images provide important information. Systematically received results can be used to confirm the quality of information about the spill source and, consequently, the quality of the assessment decisions that have been taken during the clean-up measures (such as the methods and optimal moment for the effective completion of the operation). These results will help to control environmental recovery process. It is particularly difficult to measure the thickness of 
emulsion layer and other types of viscous oil because of their limited distribution.

A false image resembling an oil spill, which may be caused by the shadow of a cloud, the convergence of cold and warm water, muddy and warm water, floating algae and sandbanks, has to be checked using a standard algorithm, the same as for a possible oil pollution. A sampling algorithm will be included in the flight mission of the RPA.

\section{Requirements for remotely piloted aircraft payload}

Each application of the RPA requires different combinations of payload attached to the aircraft. Finding an appropriate sensor is a difficult task, as the RPA is often predefined (Klimkowskaa et al., 2016).

In the visible range of electromagnetic spectrum (approximately 400 to $700 \mathrm{~nm}$ ), oil has a higher surface reflectance than water. Oil does not have specific absorption reflection tendencies in this range. Oil is generally detected in the visible spectrum mainly when an aircraft is performing a surveillance mission. The sheen shows up silvery and reflects light over a wide spectral region down to blue. As there is no strong information in the 500 to $600 \mathrm{~nm}$ region, this region is often filtered out to improve contrast (Fingas and Brown, 2014). Overall, however, oil has no specific characteristics that distinguish it from the background contrast (Fingas and Brown, 2014). Taking into account the polarizing effects of oil on water, surveillance with polarized lenses gives better results. The main challenge of oil pollution monitoring in the visible spectrum is sun. False oil pollution detections are caused by sun glitters on the surface of water. Detected in the visible spectrum, an oil slick should be confirmed by other sensors, and samples have to be taken from the water surface.

Video cameras are mainly used in conjunction with filters to improve contrast for the initial detection of a possible oil spill. This method has serious restrictions for sensing an oil spill, because oil has poor contrast and insufficient discrimination. A new generation of video cameras designed for operation in low light environments can be used for surveillance in darkness. Tests of the generation III night vision camera showed that this technology is capable of providing imagery in dark night conditions contrast (Fingas and Brown, 2014).

To increase accuracy and eliminate potentially false contamination detection, which can be caused by external factors, there is used an algorithm of oil thickness measurement with the help of multispectral imaging that provides high accuracy and is versatile for any areas of water and various meteorological and atmospheric conditions. When a sensor is a multichannel detector with several spectral bands, such a system is called a multispectral imaging system. The resulting image is a "multilayer image"; all spectral and brightness information on the observed object is included in this image.

Using multispectral images received via the RPA payloads with a multispectral camera to define oil thickness, the method of multispectral classification, in which oil film spectrum results were calibrated by thickness using the data received with the help of a sampling device. When using a multispectral camera, it is necessary to take into account the high accuracy of the results of determining the small thickness of an oil film and the possibility of determining with low accuracy for thick films.

The use of ultraviolet (UV) sensor data for oil detection has some important limitations. Oil shows high reflectance of sunlight in the UV range. UV sensors can be used to map sheens of oil, as oil slicks display high reflectivity of UV radiation even at thin layer $(<0.1 \mu \mathrm{m})$ contrast (Fingas and Brown, 2014). Thicknesses of 0.5 to $10 \mathrm{~mm}$ are needed for countermeasure purposes; these are almost 1000 times greater than those indicated by infrared contrast (Fingas and Brown, 2014). Likewise, in the case of visual assessment of oil film thickness by using the VNIR camera, for crude and fuel oil film with a thickness of approximately 0.1 to 0.2 millimeters light cannot fully penetrate through the film any more, and thus, it seems to be an almost black or very dark reflected image. A visualization system with an UV-visible wavelength camera can still accurately detect and reflect the film three-dimensional shape, but cannot be used for the assessment of actual thickness. A boundary condition has a thickness of $0.1 \mathrm{~mm}$; it may seem that the measurement of thin films is in the upper limits of sensitivity, but many oil slicks come in this range. Refined petroleum products, such as gasoline, diesel fuel, jet fuel and lube oil, usually have no image reflection with a clear color associated with the dependence of water surface film thickness, and measuring in the visible range is not possible (products reflect the UV and infrared ranges).

A SWOT analysis (Table I) was performed to initially evaluate the application of visible, UV and multispectral sensors for oil pollution monitoring. The main objective of SWOT analysis was to analyze the possibilities and opportunities of improving the RPA payload.

Hyperspectral imaging sensors have a wide variety of bandwidths in the visible spectrum to provide rich data, set and detect objects of interest better than with a single-bandwidth imaging sensor. Hyperspectral imaging is a growing area in remote sensing in which an imaging spectrometer collects hundreds of images at different wavelengths for the same spatial area (Gonzalez et al., 2013). Hyperspectral images are extremely complex and require advanced processing algorithms to satisfy near real-time requirements in applications, such as mapping of oil spills and chemical contamination. Developers of

Table I A SWOT Analysis for using visible, UV and multispectral sensors for oil pollution monitoring

\begin{tabular}{ll}
\hline Strength & $\begin{array}{l}\text { Avoiding false alarms by using different spectral bands } \\
\text { Operation in different environmental conditions }\end{array}$ \\
Can detect a very thin oil layer \\
Weakness & $\begin{array}{l}\text { False alarms caused by wind "slicks", sunlight, biogenic } \\
\text { films }\end{array}$ \\
Opportunities & $\begin{array}{l}\text { Possibility of processing on-board using the satellite } \\
\text { communication system. More detailed data analysis } \\
\text { performed aground by taking data from a storage device } \\
\text { Threats }\end{array}$ \\
& $\begin{array}{l}\text { For energy saving purposes, data are recorded to the } \\
\text { storage device only in certain coordinates } \\
\text { Limited by weather conditions } \\
\text { surface wind }>15 \mathrm{~m} / \mathrm{s} \\
\text { wave height }>2 \mathrm{~m}\end{array}$ \\
\hline
\end{tabular}


hyperspectral sensors provide flexible and customizable options for the number and resolution of visible and infrared spectral bands. The results of SWOT analysis are presented in Table II.

Oil, which is optically thick, absorbs solar radiation and reemits a portion of this radiation as thermal energy, primarily in the 8 to $14 \mu \mathrm{m}$ region. An infrared camera is mounted on the RPA as payload. The infrared camera can detect thin film temperature rather than fibrillation on the surface, because the contrast may appear cooler than the surrounding water both day and night, as oil substances have lower emissivity than water. The thicknesses at which these transitions occur are poorly understood, but evidence indicates that the transition between a hot and cold layer lies between 50 and $150 \mu \mathrm{m}$ and the minimum detectable layer is between 10 and $70 \mu \mathrm{m}$ (Pinel and Bourlier, 2010). Thinner films, as a rule, create a solar heat trap and, thus, the film top is warmer than the water during the day in sunny weather. If an oil film is very thin, it is in thermal equilibrium with the surrounding water and will not show difference in temperature (Ying and Guo-xin, 2009). After the sunset, they return to the situation when radiation is higher than the one of water because of the difference. For 24-h monitoring in the dark time, when it is impossible to use the VNIR multispectral camera, the infrared camera is mounted as the RPA payload for measuring an oil film with a thickness of more than $0.1 \mathrm{~mm}$.

The SWOT analysis of RPA payload sensors in Tables I and II demonstrates that integrated payload needs to be developed. During the analysis, it was found that to improve detection and remove false alarms, it is required to develop a sensing technique. The SWOT analysis determined that one sensor could not provide information required by the oil spill monitoring program.

The following objectives for the development of integrated payload were formulated:

- ability to apply multiple sensors for the elimination of false alarms;

Table II A SWOT analysis for using hyperspectral sensors for oil pollution monitoring

\begin{tabular}{|c|c|}
\hline Strength & Avoiding false alarms \\
\hline & Can detect all hydrocarbons \\
\hline & Can approximately define thickness of an oil film \\
\hline & $\begin{array}{l}\text { Ability to approximately detect three main types of oil } \\
\text { products }\end{array}$ \\
\hline Weakness & Limitation by solar illumination \\
\hline & $\begin{array}{l}\text { Application requires dedicated data analysis software } \\
\text { High cost }\end{array}$ \\
\hline Opportunities & $\begin{array}{l}\text { Possibility to develop through experiments databases for } \\
\text { minimizing data processing time }\end{array}$ \\
\hline & $\begin{array}{l}\text { Application of payload with both thermal and } \\
\text { hyperspectral sensors for approximate detection of oil } \\
\text { thickness }\end{array}$ \\
\hline & $\begin{array}{l}\text { A more detailed data analysis performed aground by } \\
\text { taking data from a storage device. For energy saving } \\
\text { purposes, data are recorded to the storage device only in } \\
\text { certain coordinates }\end{array}$ \\
\hline Threats & Cannot detect light oil products \\
\hline & Limited by weather conditions \\
\hline & surface wind $>15 \mathrm{~m} / \mathrm{s}$ \\
\hline & wave height $>3,5 \mathrm{~m}$ \\
\hline
\end{tabular}

Table III A SWOT Analysis for using integrated payload with multispectral, thermal and sampling device for oil pollution monitoring

\begin{tabular}{|c|c|}
\hline Strength & $\begin{array}{l}\text { Helps to avoid false alarms with } 100 \% \text { probability } \\
\text { Can detect all types of oil products } \\
\text { A sample will be transported in a container and analyzed } \\
\text { in a laboratory } \\
\text { Determining the thickness of oil film and oil on the water } \\
\text { surface }\end{array}$ \\
\hline Weakness & Results should be proved by a laboratory analysis \\
\hline Opportunities & $\begin{array}{l}\text { The use of payload with a hyperspectral sensor instead of } \\
\text { a multispectral sensor for improving detection results }\end{array}$ \\
\hline Threats & $\begin{array}{l}\text { Limited by weather conditions } \\
\text { surface wind }>18 \mathrm{~m} / \mathrm{s} \\
\text { wave height }>4 \mathrm{~m}\end{array}$ \\
\hline
\end{tabular}

- extend the time of surveillance to $24 \mathrm{~h}$ (day and night); and

- oil pollution sampling by using a special device.

The research covers the development of a method and design of a device intended for taking samples and determining the presence of oil contamination in an aquotorium area; the procedure includes taking a sample from the water surface, preparing it for transportation and delivering the sample to a designated location by using the RPA. For the optimization of RPA use, during the performance oil pollution surveillance mission, integrated payload with multispectral, thermal sensors and a sampling device was developed (Urbahs and Zavtkevics, 2017a, 2017b, EP20150174649). For this payload, a SWOT analysis was performed (Table III).

The SWOT analysis shows that the integrated payload has more advantages than a single sensor. The only threat for this application lies in very bad weather conditions.

\section{Conclusion}

The objective was to carry out the analysis of remote oil spill sensing using the RPA. The RPA provides reliable sensing of oil pollution with significant advantages over other existing methods. The objective of improving the use of the RPA was to employ all of its strong points. The reliable results of remote oil pollution sensing can be received by using an RPA payload with integrated multisystem sensors. This paper analyses the technical aspects of sensors, their advantages and limitations. To increase accuracy and eliminate potentially false contamination detection, which can be caused by external factors, there is used an algorithm of oil thickness measurement with the help of the multispectral imaging that provides high accuracy and is versatile for any areas of water and various meteorological and atmospheric conditions.

\section{References}

Colomina, I. and Molina, P. (2014), "Unmanned aerial systems for photogrammetry and remote sensing", ISPRS fournal of Photogrammetry and Remote Sensing, Vol. 92, pp. 79-97.

Fingas, M. and Brown, C.E. (2011), "Oil spill remote sensing", in Fingas, M. (Ed.), Oil Spill Science and Technology, Chapter 6, Gulf Publishing Company, New York, NY, p. 111. 
Fingas, M. and Brown, C.E. (2014), "Review of oil spill remote sensing”, Marine Pollution Bulletin, Vol. 83 No. 1, pp. 9-23.

Gonzalez, C., Sanchez, S., Paz, A., Resano, J., Mozos, D. and Plaza, A. (2013), "Use of FPGA or GPU based architectures for remotely sensed hyperspectral image processing", Integration, The VLSI fournal, Vol. 46 No. 2, pp. 89-103.

Kostianoy, A. Litovchenko, K. Lavrova, O. Mityagina, M. Bocharova, T. Lebedev, S. Stanichny, S. Soloviev, D. Sirota, A. and Pichuzhkina, O. (2006), "Operational satellite monitoring of oil spill pollution in the Southeastern Baltic Sea: 18 months experience", Environmental Research, Engineering and Management, Vol. 4 No. 38, pp. 70-77, ISSN 1392-1649.

Klimkowskaa, A. Leea, I. and Choia, K. (2016), "Possibilities of UAS for Maritime monitoring", The International Archives of the Photogrammetry, Remote Sensing and Spatial Information Sciences, Volume XLI-B1, 2016 XXIII ISPRS Congress, 12-19 July, Prague.

O’Hara, P.D., Serra-Sogas, N., Canessa, R., Keller, P. and Pelot, R. (2013), "Estimating discharge rates of oily wastes and deterrence based on aerial surveillance data collected in Western Canadian marine waters”, Marine Pollution Bulletin, Vol. 69, pp. 157-164.

Pinel, N. and Bourlier, C. (2010), "Unpolarized infrared emissivity of oil films on sea surfaces", Applied Optics, Vol. 49 No. 11, pp. 2116-2131.

Telesetsky, A. (2016), "Navigating the legal landscape for environmental monitoring by unmanned aerial vehicles", George Washington fournal of Energy \& Environmental Law, Vol. 7 No. 2.

Urbahs, A. and Jonaite, I. (2013), "Features of the use of unmanned aerial vehicles for agriculture applications", Aviation, Vol. 17 No. 4, pp. 170-175.
Urbahs, A. and Zavtkevics, V. (2014), “Oil pollution monitoring of sea aquatorium features with using unmanned aerial vehicles", Transport Means 2014: Proceedings of the 18th International Conference, Kaunas, 23-24 October, Kaunas: Technologija, pp. 75-78.

Urbahs, A. and Zavtkevics, V. (2017a), "Remotely piloted aircraft route optimization when performing oil pollution monitoring of the sea aquatorium", Aviation, Vol. 21 No. 2, pp. 70-74.

Urbahs, A. and Zavtkevics, V. (2017b), "Remote piloted aircraft using for sampling of oil spill”, Transport Means 2017: Proceedings of the 21th International Conference, Kaunas, 20-22 September, Technologija, pp. 489-492.

\section{Further reading}

Aznar, F., Sempere, M., Pujol, M., Rizo, R. and Pujol, M.J. (2014), "Modeling oil-spill detection with swarm drones", Fournal Hindawi, Abstract and Applied Analysis, Vol. 2014, Article ID 949407.

Urbahs, A. and Zavtkevics, V. (2017), "Unmanned aerial vehicle for collecting samples from the surface of water", EU patent EP3112840 (A1), 2017-01-04 (Application Nr. EP20150174649 20150630, 30.06.2015).

Ying, L., Guo-xin, L., Ji-jun, L. and Long, M. (2009), "Potential analysis of Maritime oil spill monitoring based on MODIS thermal infrared data", Geoscience and Remote Sensing Symposium, 2009, IGARSS 2009, IEEE International Conference, Vol. 3, pp. III-373-III-376, 12-17.

\section{Corresponding author}

Vladislavs Zavtkevics can be contacted at: vladz@inbox.lv 